\title{
Editorial
}

\section{Social work challenges within different countries}

by

Kjersti Ørvig

Associate Professor, PhD

University of Stavanger

kjersti.orvig@uis.no

\section{(c) (1) (-)}

This work is licensed under a Creative Commons Attribution-ShareAlike 4.0 International License. 
2016 was an active year for the Journal of Comparative Social Work. Two thematic issues were published, presenting a total of nine articles. The first issue focused on Institutional Ethnography and Comparative Social Work, while the fall issue was about Collaborative Work and Social Innovation. Consequently, many reviewers have been busy reviewing these articles, and we are very grateful for their effort.

The three contributions in this current issue all tackle the social work challenges within different countries.

The transformative reality of diverse Canadian families is outpacing national and provincial statutes and policies. This is the starting point of the article by Randy Johner and Douglas Durst: Constructing Family from a Social Work Perspective in Child Welfare: A Juggling Act at Best, which analyses the construction of "family" and decisions about family life in protection services from the perspective of professional social workers in the prairie region of Canada. The data is based on focus groups with social workers from several urban communities. The findings expose the "acceptance of diverse understanding of family", "safety and the best interest of the child" and "professional discretionary decisions" as the three primary themes that social workers use in their construction of family and decisions made about family life. During the focus group discussions, the themes of social workers' nuanced and somewhat fluid understandings of family did not always converge with current legal and professional notions of families.

The second article is by Svein Tuastad and Katya Nogales Crespo and titled, A matter of politics. The effects of the political context on social work in Norway and Bolivia, which is based on two datasets. The primary source of data includes semi-structured interviews with experts and civil servants in both Norway and Bolivia, whereas the other consists of available empirical indicators that inform the nature of the political contexts. The aim of the study is to deepen the understanding of the interplay between the political context and social work in two widely different policies - Norway and Bolivia. The main findings indicate that the effects of generally unfavourable political conditions 
permeate the possibilities of effective social work in unforeseen ways. Coordination problems, clientelism and political rivalry all lead to daily challenges on the ground. Many problems seem to reflect the overall institutional system and political culture, though in well-ordered political systems these problems are hardly an issue.

The third article is by Tarja Orjasniemi and Jona M. Olafsdottir and titled: Do we need cross border education? A case of Pilot Course Multi-professional Approaches to Substance Abuse Care and Working with Addicts. It presents a study in which the purpose is to examine students' and teachers' experiences of cross-border education based on a single course to the field of addiction and substance abuse care. The data is based on a focus group discussion, with students reflecting on the need for crossborder education, as well as the experiences and information from instructors' discussions during the planning and post-course discussions. The findings highlight four main themes, including globalization, networking, comparing theory/practice and the use of technology, with the overall experience of students and instructors being positive to cross-border education. 